\title{
Spatial Distribution of Congenital Hypothyroidism
}

\author{
Behzad Mahaki, PhD; Neda Mehrnejat, MSc²; Mehdi Zabihi MSc²; Marzie Dalvi BSc²; Maryamsadat Kazemitabaee, MSc ${ }^{2 *}$ \\ ${ }^{1}$ Department of Biostatistics, School of Health, Kermanshah University of Medical Sciences, Kermanshah, Iran \\ ${ }^{2}$ Isfahan Health Center, Isfahan University of Medical Sciences, Isfahan, Iran
}

\begin{abstract}
Background: This study was designed and conducted to investigate the spatial distribution of permanent and temporary congenital hyperthyroidism ( $\mathrm{PCH}$ and $\mathrm{TCH})$ in Isfahan.

Methods: This study was conducted on neonates who were born from March 21, 2006 to March 20, 2011 and had undergone the congenital hypothyroidism $(\mathrm{CH})$ screening program in counties affiliated to the Isfahan University of Medical Sciences. $\mathrm{CH}$ was diagnosed in 958 patients who treated with levothyroxine. The incidence rates of permanent and temporary congenital hypothyroidism in Isfahan province were calculated and their distribution was shown on the map. The space maps were drawn using the ArcGIS software version 9.3.

Results: Based on the data obtained from the screening program, the average incidence of congenital hypothyroidism in the province during the period of 2006-2011 was 2.40 infants per 1000 live births (including both PCH and TCH). The most common occurrence was in Ardestan County (10:1000) and the lowest overall incidence was observed in the Fereydounshahr county (1.39:1000). The incidence of PCH in the counties of Ardestan and Golpayegan had the highest rate in all years of study; and the greatest number of TCH cases in the five years were observed in Nain, Natanz, Khansar and Chadegan counties.

Conclusion: Adding the time dimension and performing spatial-temporal analysis is suggested because of the following items: high prevalence of $\mathrm{CH}$ in Isfahan province, the important role of this disease in mental retardation and neuropsychiatric disorder, the necessity of conducting future medical researches to find possible factors of $\mathrm{CH}$ etiology in Isfahan province, as well as necessity of performing spatial analysis with advanced statistical methods.

Keywords: Congenital hypothyroidism, Geographic Mapping, Permanent, Transient

Cite this article as: Mahaki B, Mehrnejat N, Zabihi M, Dalvi M, Kazemitabaee M. Spatial distribution of congenital hypothyroidism. Arch Iran Med. 2019;24(8):636-642. doi: 10.34172/aim.2021.90
\end{abstract}

Received: June 6, 2018, Accepted: July 7, 2019, ePublished: August 1, 2021

\section{Introduction}

Congenital hypothyroidism $(\mathrm{CH})$ is one of the most common congenital endocrine disorders, ${ }^{1}$ with a prevalence of 1 per 3000 to 4000 births. $^{2}$ It is divided into transient and permanent types and is a major cause of preventable mental retardation. ${ }^{3}$ In transient hypothyroidism, infants have normal or low serum thyroxine (T4) ${ }^{4}$ and increased serum thyroid-stimulating hormone (TSH) concentrations that may be restored with or without treatment, ${ }^{5}$ while patients with the permanent type require lifetime hormone therapy. ${ }^{6}$ Since early diagnosis and treatment of $\mathrm{CH}$ results in normal childhood in many cases of hypothyroidism, ${ }^{7}$ screening programs were developed in the early 1970s and have been accepted by many countries worldwide. ${ }^{8}$ In Iran, screening newborns for $\mathrm{CH}$ has been integrated into the National Public Health System and launched nationwide since 2005 using the protocol of TSH measured in heel prick blood spot samples in neonates within 3-5 days of birth. ${ }^{9}$ The main objective of this program is early detection and management of the affected newborns to prevent mental disability, reduce related costs and improve quality of life, and enhance the IQ of these neonates. ${ }^{10,11}$ The reported prevalence of $\mathrm{CH}$ varies in different regions, such as 1:2736 in Turkey, 1:781 in Pakistan, and 1:10000 in African Americans. ${ }^{12}$ Moreover, the average incidence of $\mathrm{CH}$ worldwide is estimated at around 1 in 3000-4000 live births, which is higher in Iran compared to the worldwide average incidence of hypothyroidism. ${ }^{13}$ There are some variations in different areas of Iran such as Tehran and Isfahan, which have an average prevalence of $\mathrm{CH}$ at 1:914 and 1:338 live births, respectively. ${ }^{13}$ Several studies have investigated different prognostic factors for $\mathrm{CH},{ }^{14,15}$ indicating the influence of several genetic and environmental factors on the incidence of this disease. ${ }^{14}$ However, some questions remain unanswered about the epidemiology of $\mathrm{CH}$, including the distribution of permanent and transient cases. ${ }^{16}$ No study has been conducted in Isfahan province to describe the geographic variation and spatial distribution of $\mathrm{CH}$. Hence, the objective of our study was to illustrate the spatial distribution of the incidence of permanent and transient $\mathrm{CH}$ using the dataset from the national newborn $\mathrm{CH}$ screening information system during 2006-2011 in counties affiliated to the Isfahan University of Medical Sciences. 


\section{Patients and Methods}

This study used an applied ecological method. The study population consisted of all live neonates born in counties affiliated to the Isfahan University of Medical Sciences from April 2006 to the end of March 2011; those confirmed as having $\mathrm{CH}$ were followed until 3 years of age. Neonates with Guthrie TSH test $\geq 5 \mathrm{mU} / \mathrm{L}$ were recalled for further investigations; those with a TSH 5-9.9 mU/L were recalled for second TSH heel prick screening tests. Finally, those with a first TSH screening $\geq 10 \mathrm{mU} / \mathrm{L}$ and second TSH screening $\geq 5 \mathrm{mU} / \mathrm{L}$ were recalled for confirmatory venous sampling. The final diagnosis was made by a pediatric endocrinologist, appointed as the focal point of the $\mathrm{CH}$ program in each county. Neonates with TSH $>10$ $\mathrm{mU} / \mathrm{L}$ and/or TT4 (total thyroxin) $<6.5 \mu \mathrm{g} / \mathrm{dL}$ in venous samples were diagnosed as having hypothyroidism ${ }^{17}$ and promptly attended to and treated by an endocrinologist. The protocol of detecting, management and follow-up is described in the national guideline. ${ }^{17}$ Technical experts of each screening center routinely register the complete data of diagnosis, management and follow-up visits of the affected neonates from birth to their last visit at the age of 3 years in related healthcare forms provided by the Ministry of Health. ${ }^{17,18}$ All findings of the current survey are based on the data extracted from the completed central healthcare forms obtained from each region. The annual incidence rates of $\mathrm{CH}$ were calculated as numbers of definitely diagnosed $\mathrm{CH}$ (permanent and transient) among all live births during one year and expressed as numbers per 1000 live births for each county. After entering the data in MS-Excel pages, drawing of the maps and spatial analysis were done using ArcGIS 9.3 software. Spatial analysis is a series of statistical methods in which the objective is to gain a precise estimation of incidence, prevalence, survival, or mortality rate of phenomena. In recent decades, methods have been developed to obtain geographical pattern and determine low- and high-risk regions for both communicable and non-communicable diseases. Health designers apply spatial analysis to recognize environmental risk factors, plan for higher quality interventions and help disease prevention. ${ }^{19}$ In Arc Map, information was entered to the attribute tables of each polygon layer and then choropleth maps with quantile classified were drawn as a raster layers in five categories and hot spots were determined. Hot spot analysis is a great statistically-based tool to assess geographic clustering. Specifically, hotspot analysis is used to pinpoint locations of statistically significant highand low-value clusters. These clusters are determined by evaluating each area within the context of neighboring areas and against all areas in the dataset. An area with high value is not necessarily a hot spot; it becomes a hot spot only when its neighbors also have high values, as opposed to simply being a data outlier. The local means for an area and its neighbors are compared proportionally with the global mean of all areas. When the observed local mean is much different than the global mean, where difference is too large to be the result of random chance, a statistically significant $z$ score results and a hot spot cluster is detected. ${ }^{20}$

\section{Results}

From April 2006 to the end of March 2011, a total of 396949 newborns were born in counties affiliated to the Isfahan University of Medical Sciences, and 958 of them were diagnosed with congenital hypothyroidism and treated with levothyroxine. According to the data obtained from the screening program, the incidence of $\mathrm{CH}$ was 3.00 (95\% CI: 1.67-4.32), 3.44 (95\% CI: 1.71-5.17), 4.96 (95\% CI: 3.50-6.43) , 3.26 (95\% CI: 1.82-4.71), 2.34 (95\% CI: 1.22-3.45), 3.43 (95\% CI: 1.97-4.89) per 1000 live births in $2006,2007,2008,2009,2010$, and 2011, respectively, showing an increasing trend from 2006 to 2008 and a decreasing trend from 2008 to 2010 (Figure 1). The results showed a high incidence of $\mathrm{CH}$ in counties affiliated to the Isfahan University of Medical Sciences that was equal to 2.40 (95\% CI: $1.83-2.98)$ per 1000 live births, which includes both transient and permanent forms of the disease. The greatest incidence was found in Ardestan county with 10 (95\% CI: 4.76-15.25) per 1000 live births, while the lowest overall incidence was observed in the Fereydounshahr County with 1.39 (95\% CI: -0.45-3.24) per 1000 live births. PCH constituted $50 \%$ of the total cases of hyperthyroidsm in the duration of the study, and 417 (50\%) were diagnosed with temporary congenital hyperthyroidism (TCH). Figure 2 shows that the incidence of PCH in the counties of Ardestan and Golpayegan had the highest rate in all study years. The highest incidence rates pertained to Ardestan, Golpayegan, Khansar and Fereydan in 2006, to Ardestan, Chadegan, Khomeinishahr, Khansar, Fereydan, Falavarjan and Golpayegan in 2007, to Ardestan, Golpayegan, Khomeinishahr, and Dehaghan in 2008, to Ardestan, Golpayegan, Tiran \& Crown in 2009, to Golpayegan, Ardestan and Khomeinishahr in 2010, and to Khansar, Ardestan, Natanz, Golpayegan, Semirom, Khomeinishahr, Lenjan, Shahreza, Borkhar \& Meimeh in 2011. The most frequent cases of TCH in the last 5 years were in counties such as Nain, Natanz,

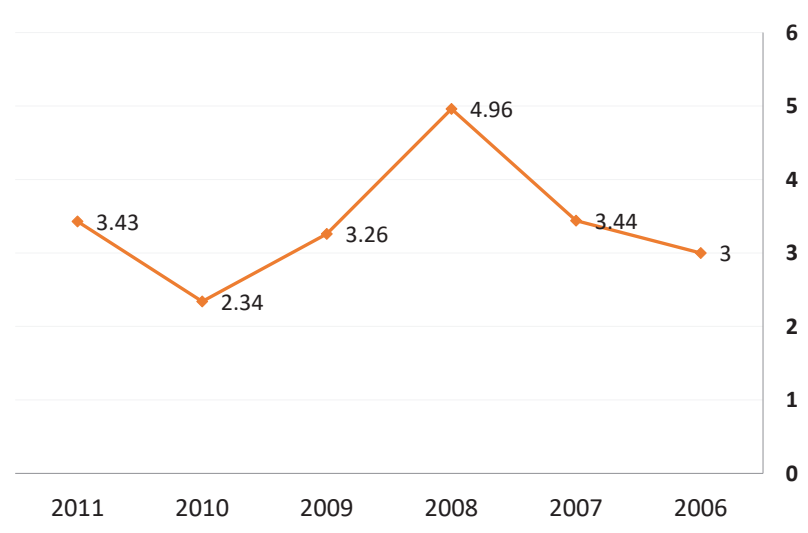

Figure 1. Trend of Incidence of Congenital Hypothyroidism During April 2006 to the End of March 2011. 


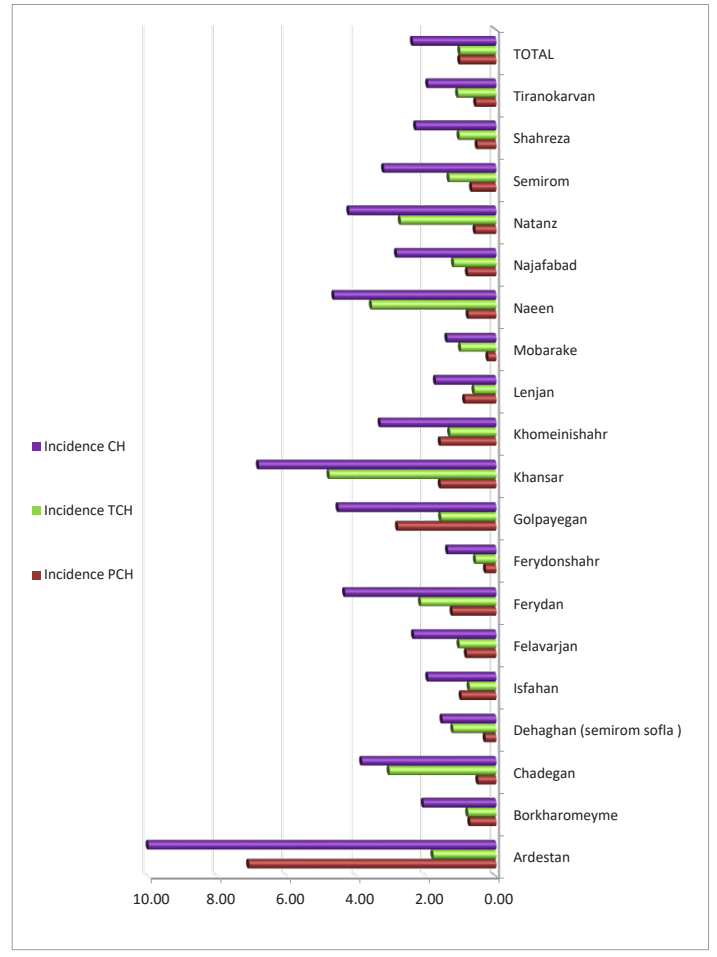

Figure 2. Hypothyroidism Incidence Rate for Each Town (2006-2011)

Khansar and Chadegan. The lowest incidence of TCH in the study period was observed in cities like Borkhar \& Meymeh, Lenjan, Fereydounshahr and Isfahan. The lowest incidence of PCH occurred in Mobarakeh, Dehaghan and Fereidounshahr.

\section{Discussion}

The results of this study indicate a high incidence of $\mathrm{CH}$ in Isfahan province, which is 2.40 (95\% CI: 1.83-2.98) per 1,000 live births; the incidence of $\mathrm{CH}$ was 3.00 (95\% CI:1.67-4.32), 3.44 (95\% CI: 1.71-5.17), 4.96 (95\% CI: 3.50-6.43), 3.26 (95\% CI: 1.82-4.71), 2.34 (95\% CI: $1.22-$ 3.45), 3.43 (95\% CI: $1.97-4.89)$ per 1000 live births from 2006 to 2011. The average incidence of $\mathrm{CH}$ worldwide is estimated at around 1 in 3000-4000 live births, which is higher in Iran compared to the average incidence of hypothyroidism in the world. ${ }^{13}$

There are some variations in different areas of Iran; for instance, in Tehran, Isfahan, Markazi province and Yazd (central cities of the country), the average prevalence rates of $\mathrm{CH}$ are reported at 1:914, 1:338, 1:307 and 1:1608 live births, respectively. ${ }^{13,21,22}$ The incidence of $\mathrm{CH}$ in Ardabil was found to be $1: 916,{ }^{23}$ whereas in the north of Iran, it was estimated at 1 per 491 live births. ${ }^{24}$ Nevertheless, the prevalence of $\mathrm{CH}$ in Iran is higher than other countries. ${ }^{21,25,26}$ In Korea, over the past 10 years, an increasing trend has been observed in the incidence of $\mathrm{CH} .{ }^{27}$ The incidence of $\mathrm{CH}$ has increased significantly in the Republic of Ireland over the past 37 years, despite having a consistent screening cut-off value. The increased rate was 0.45 cases per 1000 live births. ${ }^{28}$
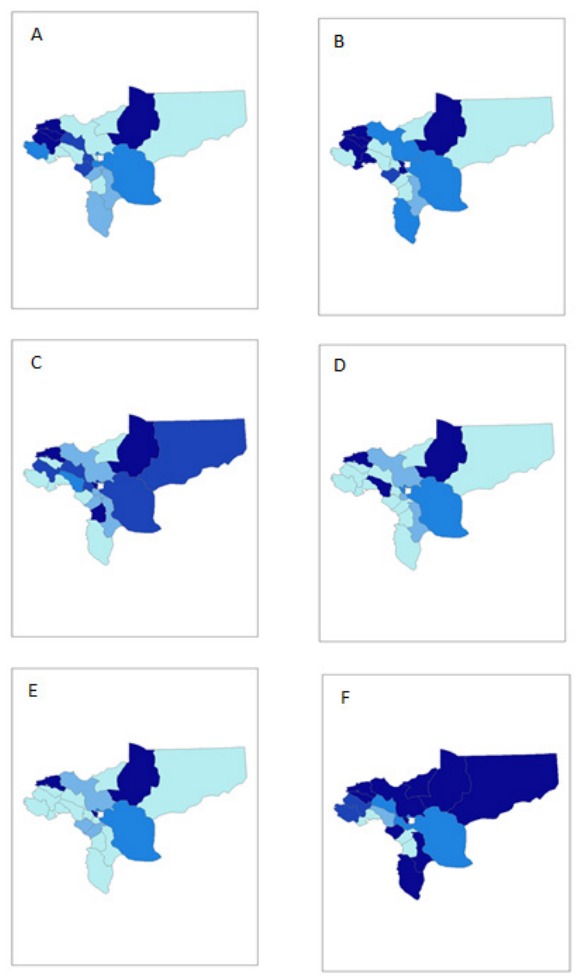

Figure 3. Spatial Distribution of Permanent Cases Hypothyroidism Incidence Rate in Isfahan Province (A:2006, B:2007, C:2008 D:2009, E:2010, F:2011).

One of the reasons for the increasing $\mathrm{CH}$ is the reduction of the cut-off levels of the neonatal hypothyroid screening program. ${ }^{29}$ Lowering the screening thresholds compared to the initial values leads to $\mathrm{CH}$ diagnosis with higher sensitivity and early intervention. ${ }^{30}$ As the cutoff levels for $\mathrm{TCH}$ is 5 in Iran, the incidence of $\mathrm{CH}$ has been recently reported at 1: $307 .{ }^{21}$ After reassessment, the incidence of permanent and transient $\mathrm{CH}$ was 1:581 and 1:628, respectively. ${ }^{21}$ In Turkey, Dill et al reported that the $\mathrm{CH}$ outbreak at an incidence of 1:469 in 2010. ${ }^{31}$

In this study, $50 \%$ of infants were diagnosed with $\mathrm{TCH}$. Although the incidence of permanent and transient hypothyroidism varies in different studies, with the expansion of using screening program, an increase is observed in transient hypothyroidism. TCH prevalence is reported between $40 \%-54 \%$ of hypothyroidism cases $^{32,33}$ which is consistent with our findings. Our findings regarding the high prevalence of TCH are consistent with the findings of Hashemipour, Doureh, Saatsaz and Medghalchi, ${ }^{21,24,33-35}$ which are markedly different from that of the Isfahan Province (79.4\%). ${ }^{1,3}$ Reports suggest that the prevalence of transient $\mathrm{CH}$ in most cases is $10 \%-$ $15 \%$ higher than that of permanent $\mathrm{CH} .{ }^{16}$ The reported prevalence rates are much lower in some countries, such as the USA $(28 \%)^{36}$ and Egypt $(17.7 \%)^{16}$ compared to the rate observed in the present study.

Our findings are inconsistent with the results of other countries which have reported TCH rate at $10 \%-15 \%$ of hypothyroidism cases. ${ }^{37} \mathrm{TCH}$ outbreaks have been 


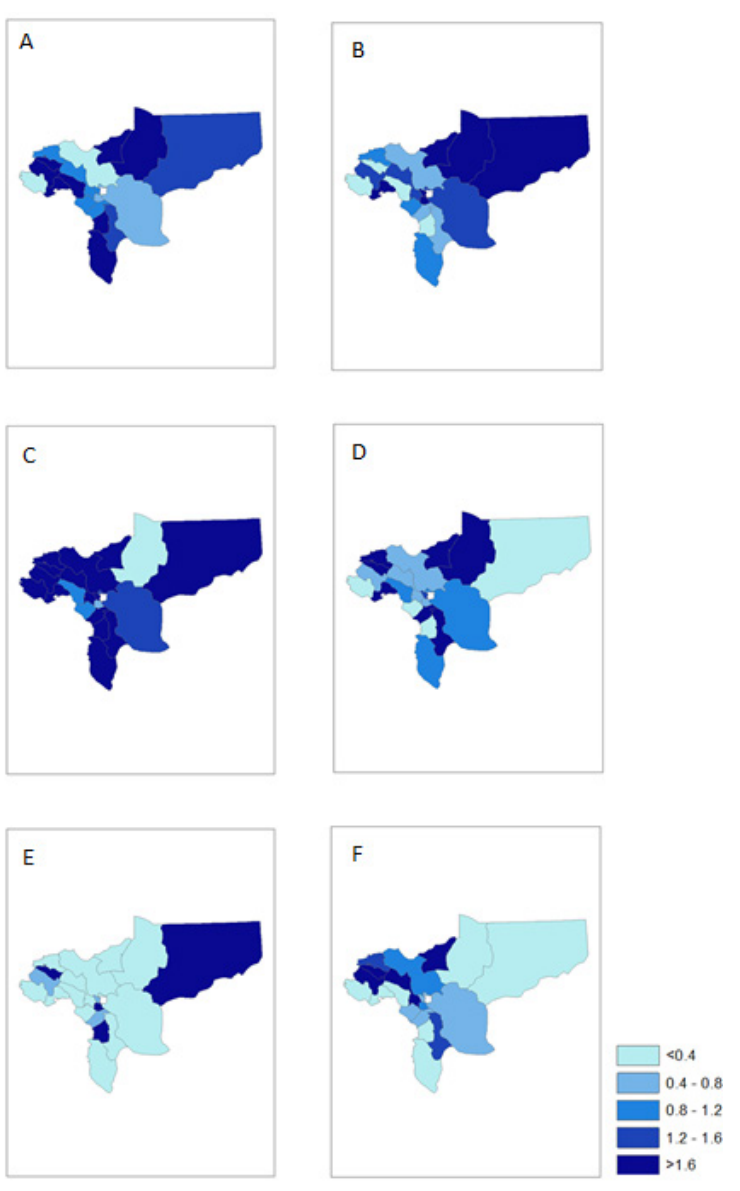

Figure 4. Spatial Distribution of Transient Cases Hypothyroidism Incidence Rate in Isfahan Province (A:2006, B:2007, C:2008, D:2009, E:2010, $\mathrm{F}: 2011)$.

reported in different studies (from 20\% to 66.5\%) ${ }^{32,37-}$ ${ }^{39}$ which are mainly due to the different definitions of $\mathrm{TCH}$ across studies. TCH may be due to risk factors such as deficiency or increased iodine, thyroid hormones blocker receptor antibodies, antithyroid drugs used by the mother during pregnancy, gene mutation, prematurity of newborn, and factors affecting the pituitary including drugs and untreated maternal hypothyroidism. ${ }^{1,33}$ Using iodine solvents in neonatal navel care and post-surgery operation care in mothers are still ongoing in both cesarean and normal delivery. ${ }^{40}$ Some recent reports indicate iodine deficiency in parts of Iran. ${ }^{41}$ A national study also demonstrated iodine deficiency in pregnant women, despite sufficiency in the iodine status of the total population. ${ }^{42}$ The studies on $\mathrm{PCH}$ prevalence have reported its rate between $46-70 \% .^{32,33,43,44}$ In this study, 1:909 live births was diagnosed with $\mathrm{PCH}$. The prevalence of $\mathrm{PCH}$ is reported in Babol at 1:1662, in Isfahan at 1:748, and in Mazandaran province 1:1043. ${ }^{24,33,45}$ However, these rates are higher than those from other regions of the world. The reported prevalence of $\mathrm{PCH}$ is 1:2679 in Canadian Quebec, 1:2418 in China, 1:2320 births in Italy and 1:2367 births in Argentina. ${ }^{29,46-48}$ This difference may be due to environmental, genetic, and immunological differences. ${ }^{16}$ One of the reasons for the increasing incidence of $\mathrm{PCH}$ is the rise in the birth of premature infants. ${ }^{27}$ Also, another main reason for the high $\mathrm{CH}$ prevalence in Iran is the high rate of consanguineous marriages. ${ }^{49}$ According to a study conducted in Wales, using the data from 11 years of screening, the incidence rate of $\mathrm{CH}$ was lower in the southern compared to the northern regions, which the authors attribute to higher population density in northern regions of Wales. ${ }^{50}$ In another study conducted in New York and the United States, differences were observed in the incidence of $\mathrm{CH}$ between different states, which the authors attributed to the Asian population in locations with higher incidence. ${ }^{51}$ In the results of the principal study conducted on the spatial distribution of $\mathrm{CH}$ in Iran, similar to the New York study, there was no specific spatial distribution for $\mathrm{CH}$ incidence, and the observed changes in the incidence of $\mathrm{CH}$ in the counties were not statistically significant. ${ }^{52}$ In the analysis of hot spots, in general, the hypothesis rate was tested. Its rate was high in some geographic regions and low in some other places, but the difference was not significant. ${ }^{52}$ Some researchers believe that geography and climatic differences can play an important role in the occurrence of $\mathrm{CH}$; therefore, further studies are needed to be conducted to test this hypothesis. ${ }^{53}$ Infantile hypothyroidism has several causes and most studies have been conducted to find out the causes of this disease. The occurrence of $\mathrm{CH}$ in Iran may be affected by environmental factors such as urbanization, and researchers have reported a higher rate of this disease in urban compared to rural children. ${ }^{54}$ The results of our study showed that Ardestan, Khansar and Golpayegan counties had the highest incidence of $\mathrm{CH}$ during the study period, and unknown factors have led to the higher incidence rate of $\mathrm{CH}$ in these cities. Moreover, the fewest cases of neonatal hypothyroidism were reported in Fereydoun Shahr, Mobarakeh, Tiran and Krone and Shahreza counties, respectively. This difference may be due to differences in weather, living conditions or different levels of iodine in geographical areas.

The limitations of our study include failure to consider risk factors such as infant sex, infant weight, having twains, maternal morbidity, type of delivery, parental consanguinity status, birth season, etc. In addition, in the early years of beginning the screening program, lack of access to all and complete information of patients and their follow-up and indistinct type of hypothyroidism (transient, permanent) in a number of patients are other limitations of our study.

This is the first study conducted on the counties of Isfahan province, which is considered as one of the provinces with high incidence of neonatal hypothyroidism, and this is one of the strengths of our study.

In conclusion, according to the prevalence of $\mathrm{CH}$ in Isfahan province and covered areas and considering the role of this disease in development of mental retardation, neuropsychiatric disorders and physical illnesses, future researches are recommended to address the main causes of $\mathrm{CH}$ and its risk factors as an issue with high priority. These 
findings need further studies to find possible factors in the etiology of $\mathrm{CH}$ disease in Isfahan province. In addition, regarding the spatial analysis with advanced statistical methods, we suggest adding the dimension of time to the study and performing spatial-temporal analysis, studying over a longer period of time and extending the protocol to cover other cities of Iran.

\section{Authors' Contributions}

BM collaborated in data processing; performed statistical analysis; NM involved in analysis and interpretation of data; $\mathrm{MZ}$ and MD helped in data collection; MS-KT conducted and managed the entire study and wrote the manuscript.

\section{Conflict of Interest Disclosures}

None.

\section{Ethical Statement}

This study was approved by ethics committee of Isfahan University of Medical Sciences with No. 293129.

\section{Acknowledgment}

The authors express their gratitude to the authorities of the Health Center of Isfahan, Iran, which helped conducting this study.

\section{References}

1. Ghasemi M, Hashemipour M, Hovsepian S, Heiydari K, Sajadi A, Hadian R, et al. Prevalence of transient congenital hypothyroidism in central part of Iran. J Res Med Sci. 2013;18(8):699-703.

2. Kliegman RM, Stanton B, Geme J, Schor N, Behrman R. Nelson Textbook of Pediatrics. Philadelphia: Saunders Elsevier, 2011:642-3.

3. Hashemipour M, Ghasemi M, Hovsepian S, Heiydari K, Sajadi A, Hadian R, et al. Prevalence of permanent congenital hypothyroidism in Isfahan-Iran. Int J Prev Med. 2013;4(12):1365-70.

4. Sperling M, Weinzimer S, Tamborlane W. Sperling Pediatric Endocrinology. Philadelphia: Saunders Company; 2008.

5. Bhavani N. Transient congenital hypothyroidism. Indian J Endocrinol Metab. 2011;15(suppl 2):S117-20. doi: 10.4103/2230-8210.83345.

6. Rastogi MV, LaFranchi SH. Congenital hypothyroidism. Orphanet J Rare Dis. 2010;5:17. doi: 10.1186/1750-11725-17

7. Grüters A, Jenner A, Krude H. Long-term consequences of congenital hypothyroidism in the era of screening programmes. Best Pract Res Clin Endocrinol Metab. 2002;16(2):369-82. doi: 10.1053/beem.2002.0202

8. Saleh DS, Lawrence S, Geraghty MT, Gallego PH, McAssey K, Wherrett DK, et al. Prediction of congenital hypothyroidism based on initial screening thyroidstimulating-hormone. BMC Pediatr. 2016;16:24. doi: 10.1186/s12887-016-0559-0.

9. Delshad H, Amouzegar A, Mirmiran P, Mehran L, Azizi F. Eighteen years of continuously sustained elimination of iodine deficiency in the Islamic Republic of Iran: the vitality of periodic monitoring. Thyroid. 2012;22(4):415-21. doi: 10.1089/thy.2011.0156.

10. Karamizadeh Z, Dalili S, Sanei-far H, Karamifard $\mathrm{H}$, Mohammadi H, Amirhakimi G. Does congenital hypothyroidism have different etiologies in Iran? Iran J Pediatr. 2011;21(2):188-92.

11. Shamshiri AR, Yarahmadi S, Forouzanfar MH, Haghdoost AA, Hamzehloo G, Holakouie Naieni K. Evaluation of current guthrie TSH cut-off point in Iran congenital hypothyroidism screening program: a cost-effectiveness analysis. Arch Iran Med. 2012;15(3):136-41.

12. Zeinalzadeh AH, Kousha A, Talebi M, Akhtari M. Screening for congenital hypothyroidism in east Azerbaijan province, Iran. J Med Screen. 2012;19(3):123-6. doi: 10.1258/ jms.2012.012024

13. Abedi M, Shahsavari S, Salehi R, Hedayati Nia S, Nasrollahi S, Sadeghi S, et al. The study of prevalence and risk factors of hypothyroidism in newborn screening program in Sanandaj city in 2009-2014. Zanko J Med Sci. 2015;15(47):46-51

14. Esmailnasab N, Moasses G, Afkhamzadeh A. Investigation of the risk factors for congenital hypothyroidism in the newborns in Kurdistan Province. Scientific Journal of Kurdistan University of Medical Sciences. 2012;17(4):1038.

15. Dalili S, Rezvany SM, Dadashi A, Medghalchi A, Mohammadi H, Dalili H, et al. Congenital hypothyroidism: a review of the risk factors. Acta Med Iran. 2012;50(11):7359.

16. Bekhit OE, Yousef RM. Permanent and transient congenital hypothyroidism in Fayoum, Egypt: a descriptive retrospective study. PLoS One. 2013;8(6):e68048. doi: 10.1371/journal.pone.0068048.

17. Yarahmadi S. National screeining program for congenital hypothyroidism, physician guideline. Tehran: Javan, 2012.

18. Mehran L, Khalili D, Yarahmadi S, Delshad H, Mehrabi Y, Amouzegar A, et al. Evaluation of the congenital hypothyroidism screening programme in Iran: a 3-year retrospective cohort study. Arch Dis Child Fetal Neonatal Ed. 2019;104(2):F176-F181. doi: 10.1136/ archdischild-2017-313720.

19. Rastaghi S, Jafari-Koshki T, Mahaki B. Application of Bayesian multilevel space-time models to study relative risk of esophageal cancer in Iran 2005-2007 at a county level. Asian Pac J Cancer Prev. 2015;16(14):5787-92. doi: 10.7314/apjcp.2015.16.14.5787

20. Getis A, Ord JK. The Analysis of Spatial Association by use of Distance Statistics. Berlin, Heidelberg: Springer; 2010: 127-45.

21. Dorreh F, Chaijan PY, Javaheri J, Zeinalzadeh AH. Epidemiology of congenital hypothyroidism in Markazi province, Iran. J Clin Res Pediatr Endocrinol. 2014;6(2):10510. doi: $10.4274 /$ Jcrpe. 1287 .

22. Ordooei M, RABIE A, Soleimanizad R, Mirjalili F. Prevalence of permanent congenital hypothyroidism in children in yazd, central Iran. Iran J Public Health. 2013;42(9):1016-20.

23. Mirzarahimi M, Barak M, Mardi A, Enteshari-Moghaddam A. Screening for congenital hypothyroidism: results of screening 5600 Ardabil province infants. Int J Sci Rep. 2017;3(11):280-4.

24. Beheshti Z, Rezaei R, Alipour A, Kosarian M, Saatsaz S. A 7-year study on the prevalence of congenital hypothyroidism in northern Iran. Electron Physician. 2018;10(4):66896696. doi: 10.19082/6689.

25. Zeinalzadeh AH, Talebi M. Neonatal screening for congenital hypothyroidism in East Azerbaijan, Iran: the 
first report. J Med Screen. 2012;19(3):123-6. doi: 10.1258/ jms.2012.012024.

26. Ford G, LaFranchi SH. Screening for congenital hypothyroidism: a worldwide view of strategies. Best Pract Res Clin Endocrinol Metab. 2014;28(2):175-87. doi: 10.1016/j.beem.2013.05.008.

27. Kang MJ, Chung HR, Oh YJ, Shim YS, Yang S, Hwang IT. Three-year follow-up of children with abnormal newborn screening results for congenital hypothyroidism. Pediatr Neonatol. 2017;58(5):442-448. doi: 10.1016/j. pedneo.2017.01.002.

28. McGrath N, Hawkes CP, McDonnell CM, Cody D, O'Connell SM, Mayne PD, et al. Incidence of Congenital Hypothyroidism Over 37 Years in Ireland. Pediatrics. 2018;142(4):e20181199

29. Olivieri A, Fazzini C, Medda E, Hypothyroidism ISGfC. Multiple factors influencing the incidence of congenital hypothyroidism detected by neonatal screening. Horm Res Paediatr. 2015;83(2):86-93. doi: 10.1159/000369394.

30. LaFranchi SH. Increasing incidence of congenital hypothyroidism: some answers, more questions. J Clin Endocrinol Metab. 2011 Aug;96(8):2395-7. doi: 10.1210/ jc.2011-1850.

31. Dilli D, Özbaş S, Acıcan D, Yamak N, Ertek M, Dilmen U. Establishment and development of a national newborn screening programme for congenital hypothyroidism in Turkey. J Clin Res Pediatr Endocrinol. 2013;5(2):73-9. doi: 10.4274/Jcrpe.929.

32. Unüvar T, Demir K, Abacı A, Büyükgebiz A, Böber E. The role of initial clinical and laboratory findings in infants with hyperthyrotropinemia to predict transient or permanent hypothyroidism. J Clin Res Pediatr Endocrinol. 2013;5(3):170-3. doi: 10.4274/Jcrpe.931.

33. Hashemipour M, Hovsepian S, Kelishadi R, Iranpour R, Hadian R, Haghighi S, et al. Permanent and transient congenital hypothyroidism in Isfahan-Iran. J Med Screen. 2009;16(1):11-6. doi: 10.1258/jms.2009.008090.

34. Ordookhani A, Mirmiran P, Hedayati M, Hajipour R, Azizi F. Screening for congenital hypothyroidism in Tehran and Damavand: an interim report on descriptive and etiologic findings, 1998-2001. Iran J Endocrinol Metabol. 2002;4(3):153-60.

35. Dalili S, Rezvani SM, Dalili H, Amiri ZM, Mohammadi $\mathrm{H}$, Kesh SA, et al. Congenital hypothyroidism: etiology and growth-development outcome. Acta Med Iran. 2014;52(10):752-6.

36. Mitchell ML, Hsu HW, Sahai I, Group MPEW. The increased incidence of congenital hypothyroidism: fact or fancy? Clin Endocrinol (Oxf). 2011;75(6):806-10. doi: 10.1111/j.13652265.2011.04128.x.

37. Korzeniewski SJ, Grigorescu V, Kleyn M, Young WI, Birbeck G, Todem D, et al. Transient hypothyroidism at 3-year follow-up among cases of congenital hypothyroidism detected by newborn screening. J Pediatr. 2013;162(1):17782. doi: 10.1016/j.jpeds.2012.06.050.

38. Hong SY, Chung HR, Lee SY, Shin CH, Yang SW. Factors distinguishing between transient and permanent hypothyroidism in patients diagnosed as congenital hypothyroidism by newborn screening. J Korean Soc Pediatr Endocrinol. 2005;10(2):154-60.

39. Rabbiosi S, Vigone MC, Cortinovis F, Zamproni I, Fugazzola
L, Persani L, et al. Congenital hypothyroidism with eutopic thyroid gland: analysis of clinical and biochemical features at diagnosis and after re-evaluation. J Clin Endocrinol Metab. 2013;98(4):1395-402. doi: 10.1210/jc.2012-3174.

40. Bezen D, Dilek E, Torun N, Tütüncüler F. Etiological evaluation of primary congenital hypothyroidism cases [in Turkish]. Turkish Archives of Pediatrics. 2017;52(2):85.

41. Nazeri P, Mirmiran P, Mehrabi Y, Hedayati M, Delshad H, Azizi F. Evaluation of iodine nutritional status in Tehran, Iran: iodine deficiency within iodine sufficiency. Thyroid. 2010;20(12):1399-406. doi: 10.1089/thy.2010.0085.

42. Delshad H, Touhidi M, Abdollahi Z, Hedayati M, Salehi F, Azizi F. Inadequate iodine nutrition of pregnant women in an area of iodine sufficiency. J Endocrinol Invest. 2016;39(7):755-62. doi: 10.1007/s40618-016-0438-4.

43. Nair PS, Sobhakumar S, Kailas L. Diagnostic re-evaluation of children with congenital hypothyroidism. Indian Pediatr. 2010;47(9):757-60. doi: 10.1007/s13312-010-0115-1

44. Tamam M, Adalet I, Bakır B, Türkmen C, Darendeliler F, Baş F, et al. Diagnostic spectrum of congenital hypothyroidism in Turkish children. Pediatr Int. 2009;51(4):464-8. doi: 10.1111/j.1442-200X.2008.02790.x.

45. Haghshenas M, Pasha YZ, Ahmadpour-Kacho M, Ghazanfari S. Prevalence of permanent and transient congenital hypothy-roidism in Babol city-Iran. Med Glas (Zenica). 2012;9(2):341-4.

46. Deladoëy J, Ruel J, Giguère Y, Van Vliet G. Is the incidence of congenital hypothyroidism really increasing? A 20-year retrospective populationbased study in Quebec. J Clin Endocrinol Metab. 2011;96(8):2422-9. doi: 10.1210/jc.2011-1073.

47. Sun Q, Chen YL, Yu ZB, Han SP, Dong XY, Qiu YF, et al. Long-term consequences of the early treatment of children with congenital hypothyroidism detected by neonatal screening in Nanjing, China: a 12-year follow-up study. J Trop Pediatr. 2012;58(1):79-80. doi: 10.1093/tropej/fmr010

48. Chiesa A, Prieto L, Mendez V, Papendieck P, de Luján Calcagno M, Gruñeiro-Papendieck L. Prevalence and etiology of congenital hypothyroidism detected through an argentine neonatal screening program (1997-2010). Horm Res Paediatr. 2013;80(3):185-92. doi: 10.1159/000354409.

49. Hashemipour M, Amini M, Talaie M, Kelishadi R, Hovespian S, Iranpour R, et al. Parental consanguinity among parents of neonates with congenital hypothyroidism in Isfahan. Eastern Mediterranean Health Journal. 2007;13(3): 567-74. doi:10665/117285

50. Law W, Bradley D, Lazarus J, John R, Gregory J. Congenital hypothyroidism in Wales (1982-1993): demographic features, clinical presentation and effects on early neurodevelopment. Clin Endocrinol (Oxf). 1998;48(2):201-7. doi: 10.1046/j.13652265.1998.3791206.x

51. Harris KB, Pass KA. Increase in congenital hypothyroidism in New York State and in the United States. Mol Genet Metab. 2007;91(3):268-77. Erratum in: Mol Genet Metab. 2008 May;94(1):140. 
52. Osooli M, Haghdoost A, Yarahmadi S, Foruzanfar M, Dini M, Holakouie Naieni K. Spatial distribution of congenital hypothyroidism in Iran using geographic information system. Iranian J Epidemiol. 2009;5(1):18.

53. Rezaeian S. Difference in the incidence of congenital hypothyroidism among world countries. Ann Saudi Med. 2013;33(6):633-4. doi:
10.5144/0256.4947.2013.633.

54. Keshavarzian E, Valipoor AA, Maracy MR. The incidence of congenital hypothyroidism and its determinants from 2012 to 2014 in Shadegan, Iran: a case-control study. Epidemiol Health. 2016;38:e2016021. doi: 10.4178/epih.e2016021.

(c) (1) (c) 2019 The Author(s). This is an open-access article distributed under the terms of the Creative Commons Attribution License (http://creativecommons org/licenses/by/4.0), which permits unrestricted use, distribution, and reproduction in any medium, provided the original work is properly cited. 